\title{
Quasi-stationary planetary waves in late winter Antarctic stratosphere temperature as a possible indicator of spring total ozone
}

\author{
V. O. Kravchenko ${ }^{1}$, O. M. Evtushevsky ${ }^{1}$, A. V. Grytsai ${ }^{1}$, A. R. Klekociuk ${ }^{2}$, G. P. Milinevsky ${ }^{1}$, and Z. I. Grytsai ${ }^{1}$ \\ ${ }^{1}$ Space Physics Laboratory, Kyiv National Taras Shevchenko University, Kyiv, Ukraine \\ ${ }^{2}$ Ice, Ocean, Atmosphere and Climate Program, Australian Antarctic Division, Kingston, Tasmania, Australia \\ Correspondence to: G. P. Milinevsky (genmilinevsky@gmail.com)
}

Received: 2 July 2011 - Published in Atmos. Chem. Phys. Discuss.: 26 October 2011

Revised: 24 February 2012 - Accepted: 12 March 2012 - Published: 23 March 2012

\begin{abstract}
Stratospheric preconditions for the annual Antarctic ozone hole are analyzed using the amplitude of quasistationary planetary waves in temperature as a predictor of total ozone column behaviour. It is found that the quasistationary wave amplitude in August is highly correlated with September-November total ozone over Antarctica with correlation coefficient $(r)$ as high as 0.83 indicating that quasi-stationary wave effects in late winter have a persisting influence on the evolution of the ozone hole during the following three months. Correlation maxima are found in both the lower and middle stratosphere. These likely result from the influence of wave activity on ozone depletion due to chemical processes, and ozone accumulation due to largescale ozone transport, respectively. Both correlation maxima indicate that spring total ozone tends to increase in the case of amplified activity of quasi-stationary waves in late winter. Since the stationary wave number one dominates the planetary waves that propagate into the Antarctic stratosphere in late austral winter, it is largely responsible for the stationary zonal asymmetry of the ozone hole relative to the South Pole. Processes associated with zonally asymmetric ozone and temperature which possibly contribute to differences in the persistence and location of the correlation maxima are discussed.
\end{abstract}

\section{Introduction}

For over three decades, significant depletion of stratospheric ozone has taken place each austral spring over Antarctica. During the 1990s and 2000s, the September mean ozone hole area, measured as the area where the total ozone column (TOC) was less than 220 Dobson Units (DU), was approximately 20-25 million square kilometres $\left(\mathrm{Mkm}^{2}\right)$ (NOAA, 2009). Over this time period, the September area grew during the 1980s and levelled off in recent years (e.g. Newman et al., 2004). However, in certain years this metric has been considerably smaller, being $17 \mathrm{Mkm}^{2}$ in 2004 and $11 \mathrm{Mkm}^{2}$ in 2002 (NOAA, 2009). Understanding the processes that influence interannual variability of the ozone hole is important for comparison of observations with modelled ozone recovery scenarios.

Overall, it is clear that the level of year-to-year variability in the size of the ozone hole during the past two decades has been influenced more by fluctuations in dynamical forcing from planetary scale waves in the atmosphere and less by changes in stratospheric chlorine levels (Shindell et al., 1997; Randel et al., 2002; Salby and Callaghan, 2004; Weber et al., 2011). Years with stronger planetary wave activity at extratropical southern latitudes are generally associated with smaller ozone holes. Dynamical variability of the ozone hole has increased in the last decade. In addition to 2002 and 2004, the ozone holes of 2007 and 2010 were less severe than normal (Tully et al., 2008; WMO, 2010). In this regard, two processes which relate to the timing of the enhanced wave activity are important.

Firstly, planetary wave (PW) activity during the winter can warm and weaken the polar vortex, limiting the extent of halogen activation by Polar Stratospheric Clouds (PSC). This "preconditioning" lessens the overall severity of spring ozone loss, as demonstrated in observational and model studies (Shindell et al., 1997; Allen et al., 2003; Huck et al., 2005; Weber et al., 2011). Secondly, the timing of the breakdown of the polar vortex has an important influence on the overall magnitude of ozone loss. The breakdown of the vortex, which may proceed rapidly through stratospheric

Published by Copernicus Publications on behalf of the European Geosciences Union. 
warming episodes, is driven by planetary waves. As observed in 2002, both preconditioning and an unprecedented sudden stratospheric warming resulted in an anomalously small ozone hole for that year (Varotsos, 2002; Allen et al., 2003).

Preconditioning wave activity can influence stratosphere temperature not only from the upward and poleward flux of wave energy from the troposphere but also by ozone transport. Strong winter PW forcing leads to larger transport of ozone in the stratospheric mean meridional circulation, known as the Brewer-Dobson circulation (BDC) that results in enriched ozone and higher stratospheric temperature in the extratropics (Randel et al., 2002; Salby and Callaghan, 2004; Hood and Soukharev, 2005; Weber et al., 2011). The co-action of dynamics, transport and chemistry is important, for example, in producing the fall-spring ozone correlation found in the Arctic (Kawa et al., 2005; Sinnhuber et al., 2006).

In this work, we statistically analyze the relationship between austral late-winter PW activity in the Antarctic polar vortex region and the behaviour of the ozone hole in spring. As an indicator of dynamical activity in the late winter, the quasi-stationary wave (QSW) amplitude in the zonal distribution of stratospheric temperature in August is used. It is known that the quasi-stationary planetary wave of zonal wave number 1 (QSW1) dominates the Southern Hemisphere (SH) stratosphere (Randel, 1988; Wirth, 1993; Grytsai et al., 2007; Gabriel et al., 2011) leading to steady displacements of the stratospheric polar vortex relative to the pole (e.g. Waugh and Randel, 1999). This, in turn, results in zonal asymmetry of the ozone and temperature fields (Wirth, 1993; Salby and Callaghan, 2004; Grytsai et al., 2007; Canziani et al., 2008). Recent studies show that zonal asymmetry in ozone can influence the planetary wave propagation and zonal mean circulation in the polar stratosphere (Crook et al., 2008; McCormack et al., 2011; Albers and Nathan, 2012). Due to the QSW1 dominance, the QSW amplitude in our analysis could be considered as an approximate measure of the zonal asymmetry in the SH stratospheric temperature. We then consider possible effects of this zonal asymmetry in the preconditioning of the spring ozone hole.

It has been shown by Grytsai et al. (2008) that a large increase of the QSW amplitude in August preceded anomalously diminished ozone holes in 1988 and 2002, whereas no preconditioning effects were observed in July. We assume that the dynamical conditions in the vortex region in August (mainly due to QSW activity) may affect both the early stage and further spring evolution of the ozone hole. Here we statistically analyze the association between the QSW amplitude in August and characteristics of the ozone hole over the $26 \mathrm{yr}$ period 1985-2010. The paper is organized as follows. Section 2 describes the data sets and methods used, Sect. 3 presents the results, Sect. 4 discusses the interpretation of the results, and conclusions are given in Sect. 5.

\section{Data and method}

Late winter zonal anomalies in stratospheric air temperature were examined with National Centers for Environmental Prediction-National Center for Atmospheric Research (NCEP-NCAR) Reanalysis data (Kalnay et al., 1996) from http://www.esrl.noaa.gov/psd/data/reanalysis. The monthly mean zonal temperature distributions in August were considered. Since the quasi-stationary wave at high southern latitudes is dominated by wave 1 (Sect. 1), we have not formally Fourier analyzed the temperature data. Instead, we simply define the QSW amplitude, $A_{\mathrm{QSW}}$, as one half of the difference between the peak maximum and minimum temperature along a given latitude circle at a given pressure level. An illustration of how this is done is shown in Fig. 1.

For our analysis, we created time series of $A_{\mathrm{QSW}}$ values for seven latitude circles between $50^{\circ} \mathrm{S}$ and $80^{\circ} \mathrm{S}$ with 5degree steps and at the five pressure levels 150, 100, 50, 30 and $10 \mathrm{hPa}(13-32 \mathrm{~km})$ over the $1985-2010$ period. The analysis is restricted to $26 \mathrm{yr}$ to examine the available principal ozone hole years (e.g. Newman et al., 2004). The dominant QSW1 contribution is clearly seen from the single zonal maximum near $180^{\circ} \mathrm{E}$ on both curves in Fig. 1, which display the extreme conditions in the winter southern stratosphere with weak (2002, solid curve) and strong (2006, dashed curve) stratospheric polar vortices. These two events represent a range of dynamical variability in waveozone coupling in the Antarctic stratosphere (Weber et al., 2011; their Fig. 4).

The QSW climatology in latitude-altitude coordinates is shown by the amplitude $A_{\mathrm{QSW}}$ and its standard deviation (SD) in August in Fig. 2a and b, respectively. The amplitude tends to increase vertically and decrease poleward (south of $60^{\circ} \mathrm{S}$ ) with maximum and minimum values of $8.1 \mathrm{~K}$ and $1.6 \mathrm{~K}$, respectively (Fig. 2a). The maximum amplitude at $10 \mathrm{hPa}$ (Fig. 2a) relates to a general amplification of largescale planetary waves between the lower and middle stratosphere (Matsuno, 1970; Randel, 1988). Peak values at $60^{\circ} \mathrm{S}$ correspond to the mean climatological position of the polar night jet at the stratospheric polar vortex edge in Antarctic winter with a strong temperature gradient across it (Waugh and Randel, 1999; Karpetchko et al., 2005). As planetary waves disturb the vortex shape and position, the zonal temperature deviations and, hence $A_{\mathrm{QSW}}$, maximize around the mean position of the displaced vortex edge. It is seen that the SD distribution with maximum of $4.6 \mathrm{~K}$ and minimum of $0.6 \mathrm{~K}$ (Fig. 2b) is similar to the $A_{\mathrm{QSW}}$ distribution (Fig. 2a). A minor distinction is that there is a slightly wider latitude extension for the region of maximum variability $\left(60^{\circ}-65^{\circ} \mathrm{S}\right.$ in Fig. 2b) in comparison with the position of the $A_{\mathrm{QSW}}$ maximum $\left(60^{\circ} \mathrm{S}\right.$ in Fig. 2a). These climatological distributions are important in the interpretation of the spring ozone response to late-winter QSW activity (Sect. 4).

The ozone hole was characterized by monthly mean parameters of three types: 


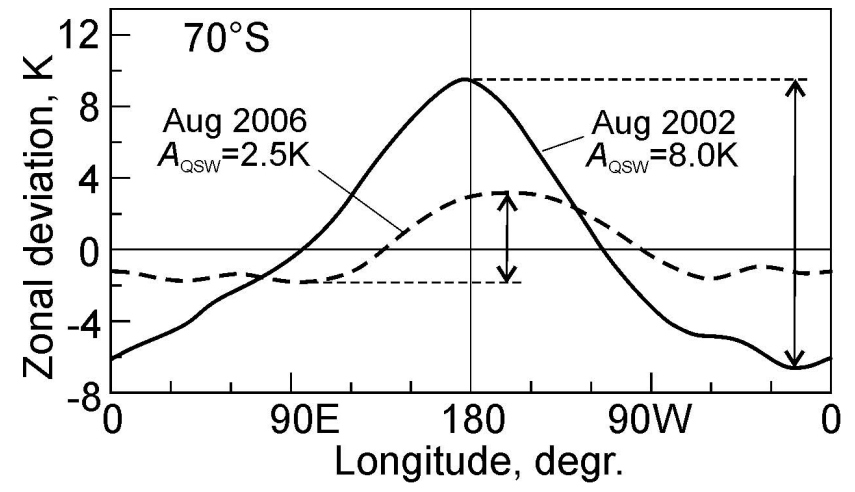

Fig. 1. Zonal anomalies of $100 \mathrm{hPa}$ temperature at $70^{\circ} \mathrm{S}$ in $\mathrm{Au}-$ gust 2002 (solid curve) and August 2006 (dashed curve) as an illustration of weak and strong vortex conditions, respectively.

1. OHA - the overall size of the ozone hole characterized by the monthly mean ozone hole area for September, October and November using data of (NOAA, 2009, Fig. 8) for 1985-2008 and data from http://www.cpc. ncep.noaa.gov/products/stratosphere/polar/polar.shtml for 2009 and 2010.

2. $\mathrm{TOC}_{\mathrm{zm}}$ - the zonal mean total ozone column at latitudes of $60^{\circ} \mathrm{S}, 70^{\circ} \mathrm{S}$ and $80^{\circ} \mathrm{S}$ used to represent TOC variations at the edge of and inside the ozone hole. These values were collected from gridded satellite data obtained by Nimbus-7 Total Ozone Mapping Spectrometer (TOMS, 1979-1992; McPeters et al., 1996), Earth Probe TOMS (1996-2005; McPeters et al., 1998), and Aura Ozone Monitoring Instrument (2006-2010; Dobber et al., 2008) available at http://ozoneaq.gsfc.nasa. gov/measurements.md. Note that a data gap exists in $\mathrm{TOC}_{\mathrm{zm}}$ at $80^{\circ} \mathrm{S}$ during September, when, on average, 18 days of measurements are available. Multi Sensor Reanalysis (MSR) data based on the TM3DAM assimilation scheme (van der A et al., 2010) were used for the 1993-1995 period (http://www.temis.nl/protocols/ o3field/o3mean_msr.php).

3. TOC $_{\mathrm{SP}}$ - the Amundsen-Scott total ozone column derived from ground-based measurements at South Pole (http://www.esrl.noaa.gov/gmd/ozwv/dobson/ams. $\mathrm{html}$ ) and used as an independent time series showing the TOC variability in the vortex core. Ozone measurements here do not provide complete datasets of $\mathrm{TOC}_{\mathrm{SP}}$ for October and November. The number of days when the measurements were made was on average 14 and 25 in October and November, respectively, during 19852008. In September, ozone spectrophotometer observations are impossible at South Pole due to polar night and we have filled the data gap for this month using stratospheric temperature data as a proxy. It is known that the lower stratosphere temperatures are highly correlated
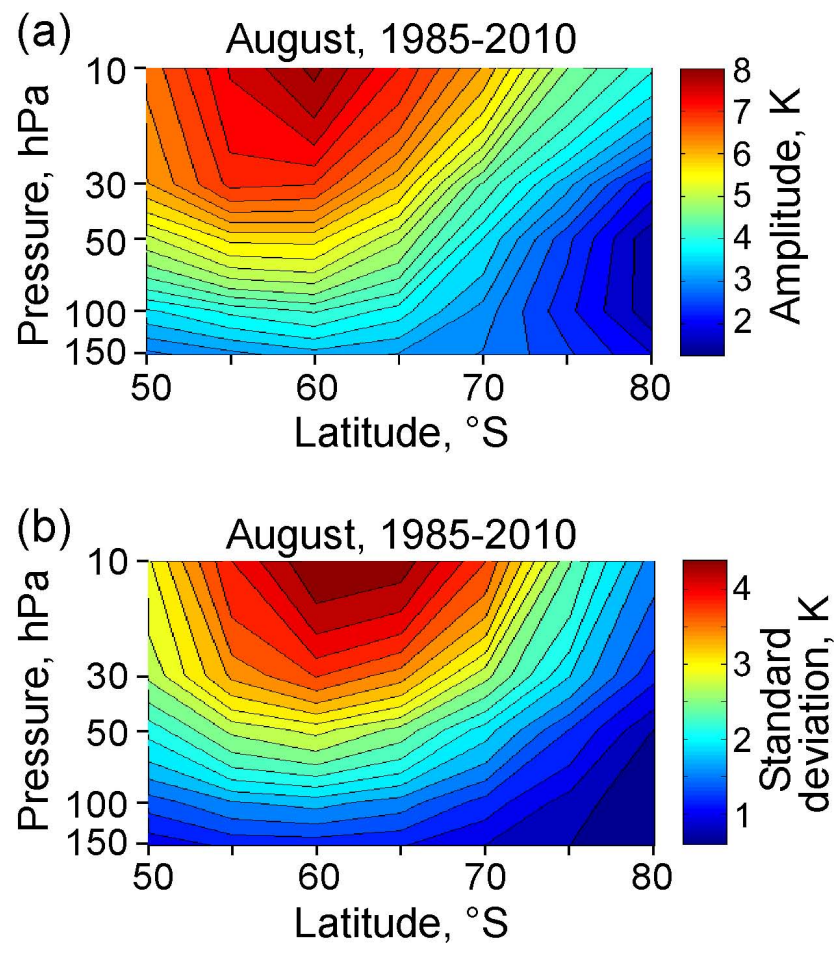

Fig. 2. Climatology of the 1985-2010 period for (a) the QSW amplitudes in Antarctic stratosphere temperature in August between $50^{\circ} \mathrm{S}$ and $80^{\circ} \mathrm{S}$ and (b) the amplitude standard deviations.

with total ozone (Wirth, 1993; Randel and Cobb, 1994; Solomon et al., 2005) and the temperature time series can therefore be used to infer the interannual TOC variability. The time series of the stratospheric temperature over the South Pole for September, $T_{\mathrm{SP}}$, was created by averaging the NCEP-NCAR reanalysis temperatures at $90^{\circ} \mathrm{S}$ over seven standard pressure levels 150 , $100,70,50,30,20$, and $10 \mathrm{hPa}(13-32 \mathrm{~km})$. Thus, this data set characterizes interannual temperature variability over the South Pole in the partial column of the atmosphere between the lower and middle stratosphere, in the layer containing the maximum ozone amount (e.g. Solomon et al., 2005).

Similarly, because the TOC observations did not provide complete time series in late winter at the latitudes $60^{\circ}-90^{\circ} \mathrm{S}$, the vertically averaged temperatures were used to create time series of the zonal mean temperatures, $T_{\mathrm{zm}}$, in August. This enabled us to indirectly estimate a preconditioned state of the coupling between $A_{\mathrm{QSW}}$ and ozone in Antarctic stratosphere.

The linear (Pearson) correlation coefficient, $r$, between the $A_{\mathrm{QSW}}$ time series and ozone hole parameters, $\mathrm{OHA}, \mathrm{TOC}_{\mathrm{zm}}$, $T_{\mathrm{zm}}, \mathrm{TOC}_{\mathrm{SP}}$, and $T_{\mathrm{SP}}$ was calculated. Linear (non-linear with polynomial 3 fitting) trends were subtracted from the $A_{\mathrm{QSW}}, T_{\mathrm{zm}}$ and $T_{\mathrm{SP}}\left(\mathrm{OHA}, \mathrm{TOC}_{\mathrm{zm}}\right.$ and $\left.\mathrm{TOC}_{\mathrm{SP}}\right)$ time series (nonlinearity in the long-term changes of the Antarctic total ozone in spring, as noted in Sect. 1, is due to a transition 
from relatively monotonic TOC decrease during the 1980s first half of 1990s to a levelling off after the mid-1990s; corresponding changes in the ozone hole area and ozone mass deficit have occurred; e.g. Newman et al., 2004; Huck et al., 2005).

We use the linear correlation method in our analysis considering the previous studies of the relationships between the planetary wave activity and polar total ozone (e.g. Salby and Callaghan, 2004; Huck et al., 2005; Weber et al., 2011). Weber et al. (2011) investigated the BDC impact on ozone buildup in the Arctic and Antarctic regions and have shown that a compact linear relationship exists between the winter eddy heat flux (a measure of the vertical propagation of planetary waves from the troposphere used to describe variations in the BDC driving) and the spring-to-fall ozone ratio (their Fig. 4). This result demonstrates the broad range of the dynamical disturbances in winter which are linearly coupled with the polar TOC changes in spring: from low wave activity and large Antarctic ozone hole in 2006 to high wave activity and the diminished ozone hole in 2002 and further to the cold and warm Arctic winters.

We have compared the use of the two methods, Pearson linear correlation and Spearman rank correlation for the analyzed time series (Fig. 3). As an example, we present the relationships between the two data sets, the QSW amplitude in August inside the polar vortex $\left(70^{\circ} \mathrm{S}, 10 \mathrm{hPa}\right)$ and the ozone hole area in October during 1985-2010 (Fig. 3a). The long-term tendencies in these parameters are different: nonmonotonic changes of the ozone loss in Antarctic ozone hole and in its size, as noted above (Newman et al., 2004; Huck et al., 2005) and an absence of the clear tendency in the QSW amplitude at the individual pressure levels (not shown). As a result, the scatter diagram in Fig. 3a shows neither purely monotonic nor linear association between the variables. It is seen from Fig. $3 b$ that the anomalies of the detrended time series tend to be linearly coupled with the Pearson linear correlation coefficient $r=-0.78$ (significant at the $1 \%$ level using Student's t-test). This tendency is in agreement with the linear wave-ozone association from other studies (Salby and Callaghan, 2004; Huck et al., 2005; Weber et al., 2011).

Since a monotonic relationship is an important underlying assumption of the Spearman rank correlation and this method is less sensitive to outlying values (Wilks, 2011), the Spearman rank correlation coefficient is smaller, $r_{\mathrm{S}}=-0.41$ (Fig. 3c), than the r-value (Fig. 3b). Two outliers in our data are diminished ozone holes 1988 and 2002 (two points in the lower right corners of the Fig. $3 a$ and $b$ ), which are responses to the enhanced PW activity. They represent the real range of the dynamical impacts on the Antarctic total ozone, as noted above. For very large ozone holes, their size has almost reached a threshold in the mid-1990s (e.g. Newman et al., 2004) and this corresponds to the points in the upper left corner of scatter plots in Fig. 3a and b. After exclusion of the anomalous years 1988 and 2002 from the linear correlation, the correlation coefficient remains rather high, $r=-0.56$ (significant at the $1 \%$ level), that is evidence of the prevailing linear coupling between the correlated variables and of the proper use of the correlation method in this study. Since the Spearman rank correlation is less sensitive to outliers, the extent of the statistical dependence between the variables is likely underestimated by this method (Fig. 3c).

The correlation significance was estimated with a Student's t-test and without accounting for the lag-1 autocorrelation of the correlated time series, as is usually done in climate-related studies (e.g. Ciasto and Thompson, 2008). Spring total ozone usually has low correlation to ozone anomalies in the previous calendar year in both hemispheres (Fioletov and Shepherd, 2003) and autocorrelation in the $A_{\mathrm{QSW}}$ time series is too low $(r<0.1$ in most cases under consideration) to take into account an effective sample size reduction in significance testing.

Based on the QSW climatology at $100 \mathrm{hPa}$, Grytsai et al. (2008) noted that QSW amplitudes in July and August have a similar latitudinal distribution between $50^{\circ} \mathrm{S}$ and $80^{\circ} \mathrm{S}$. The strong QSW activity in August was the only preconditioning effect in the occurrences of small ozone holes in 1988 and 2002. We have compared the preconditioning potential of $A_{\mathrm{QSW}}$ in July and August using time series for $65^{\circ} \mathrm{S}, 100 \mathrm{hPa}$, over the 1985-2010 period. Correlation coefficients between $A_{\mathrm{QSW}}$ and ozone hole area averaged over September-November are: $r=-0.19$ (statistically insignificant) for QSW in July and $r=-0.64$ (significant at the $1 \%$ level) for QSW in August. This obvious difference is also shown by the r-values in Table 1.

It is seen from Table 1 that, in contrast to July, variations of the QSW amplitude in August and ozone hole area in spring months are closely coupled $(r<-0.5$ in five cases, all significant at the $1 \%$ level). At $100 \mathrm{hPa}(10 \mathrm{hPa})$ the correlation reaches a negative value of $r=-0.65(r=-0.76)$. For July, a single value of $r=-0.43$ is statistically significant at the $5 \%$ level. The comparison shows that stratospheric disturbances associated with QSW anomalies in August result in a noticeably stronger response in the spring ozone hole than those in July. In the next section, we analyze quantitative relationships between the late-winter QSW anomalies at selected latitudes and pressure levels and the spring ozone hole parameters indicated above.

\section{Results}

Figure 4 summarizes the correlation distributions. The plot axes represent the latitude-altitude ranges for the preconditioned QSW amplitude anomalies, $A_{\mathrm{QSW}}\left(50^{\circ}-80^{\circ} \mathrm{S}, 150\right.$ $10 \mathrm{hPa}$ ). Four panels, AUG, SEP, OCT and NOV, demonstrate seasonal changes in the responses of the ozone hole parameters during August, September, October and November, respectively, to the $A_{\mathrm{QSW}}$ variations. Note that panel AUG shows a degree of this coupling under preconditioned (latewinter) state of the Antarctic stratosphere. Columns (a-d) 

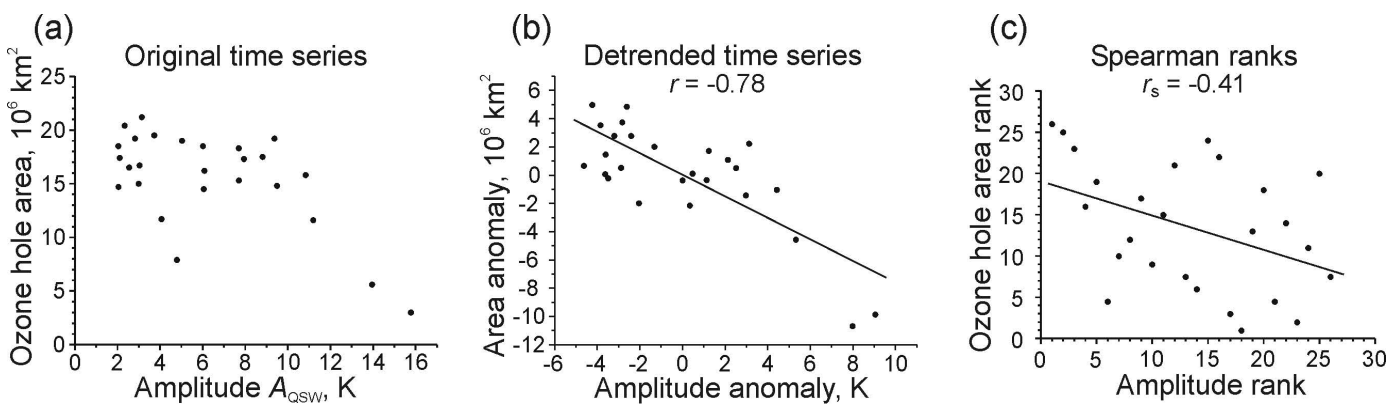

Fig. 3. Relationships between the variations of the ozone hole area in October and the QSW amplitude in August at $70^{\circ} \mathrm{S}, 10 \mathrm{hPa}$, during 1985-2010: (a) original data, (b) detrended anomalies and (c) Spearman ranks.

Table 1. Correlation coefficients $(r)$ of the QSW amplitude at $65^{\circ} \mathrm{S}$ in July and August with the monthly mean ozone hole area in September-November. The r-values that are significant at the $1 \%$ level (5\% level) are in bold (in italics).

\begin{tabular}{lrrr}
\hline \multirow{2}{*}{ QSW amplitude, } & \multicolumn{3}{c}{ Ozone hole area, month } \\
\cline { 2 - 4 } month \& pressure level & Sep & Oct & Nov \\
\hline July, $10 \mathrm{hPa}$ & -0.28 & -0.43 & -0.35 \\
July, $100 \mathrm{hPa}$ & -0.07 & -0.15 & -0.26 \\
August, $10 \mathrm{hPa}$ & $\mathbf{- 0 . 5 1}$ & $\mathbf{- 0 . 7 6}$ & $-\mathbf{0 . 6 1}$ \\
August, $100 \mathrm{hPa}$ & $\mathbf{- 0 . 5 9}$ & $\mathbf{- 0 . 6 5}$ & -0.32 \\
\hline
\end{tabular}

display the poleward changes in the responses of the zonal means (total ozone, $\mathrm{TOC}_{\mathrm{zm}}$, and vertically averaged temperature, $T_{\mathrm{zm}}$ and $T_{\mathrm{SP}}$ ) between $60^{\circ} \mathrm{S}$ and $90^{\circ} \mathrm{S}$ and column (e) is the response in the ozone hole area.

The data set size used in this study ( $26 \mathrm{yr}$ ) produces correlation coefficient values $|r| \geq 0.47$ that are statistically significant at the $1 \%$ level and less, based on Student's t-test. Red and dark-red in each plot show where the QSW disturbances cause maximum impact on the dependent variables (correlation peaks in Fig. 4 are shown with two decimal places). Negative correlation for the ozone hole area (Fig. 4e) is shown in the same colour scale as positive correlations on the rest of plots.

One can see from Fig. 4, that the contours of $r=0.5-0.8$ (for simplicity, we give modulus of the correlation coefficients hereafter) cover much or all of the individual plots except for Fig. 4a, NOV (response in $\mathrm{TOC}_{\mathrm{zm}}$ at $60^{\circ} \mathrm{S}$ ). This is evidence that the high sensitivity of the zonal mean ozone and temperature and the ozone hole area to the late-winter QSW variability persists over four months, from August to November. It is concluded from general closeness of the correlation patterns in panels SEP-NOV to those in panel AUG (Fig. 4) that the preconditioned QSW effects in the Antarctic stratospheric temperature have their main features in the spring ozone/temperature variability. Overall positive coupling means a warmer Antarctic stratosphere and higher TOC level over the latitudes $60^{\circ}-90^{\circ} \mathrm{S}$ under stronger QSW activity. The prevailing QSW1 contribution (Sect. 1) to temperature field disturbances estimated by $A_{\mathrm{QSW}}$ suggests that variability in the zonal asymmetry of the Antarctic polar vortex in late winter could underlie the positive correlations in Fig. 4 (see Sect. 4.2). Note that some correlated pairs display the close ozone-temperature relation mentioned in Sect. 2 that could be seen in the similarity between the correlation patterns for zonal mean total ozone (Fig. 4b and c, SEP) and zonal mean temperature (Fig. 4b, AUG; Fig. 4d, SEP).

In the vertical, the two correlation maxima are noted in Fig. 4. In the lower stratosphere (150-50 hPa, or $13-21 \mathrm{~km})$, correlation maxima appear in AUG, reach $r=0.81$ in SEP and disappear in OCT and NOV. Correlation maxima in the middle stratosphere (near $10 \mathrm{hPa}$, or $32 \mathrm{~km}$ ) exist from AUG to NOV (maximum $r=0.83$ ) and they are displaced by latitude from $75^{\circ} \mathrm{S}$ to $60^{\circ} \mathrm{S}$, respectively. In most cases, correlation peaks in lower and middle stratosphere are associated with the $A_{\mathrm{QSW}}$ variations near $70^{\circ} \mathrm{S}$. Clear vertical separation of the maxima is evidence for two different sources of the preconditioning effect in the lower and middle stratosphere.

Correlation maxima in the lower stratosphere do not relate to the late-winter QSW climatology (Fig. 2). Notably they are absent in $\mathrm{TOC}_{\mathrm{zm}}$ at the latitude circle $60^{\circ} \mathrm{S}$ (Fig. 4a) which is usually outside the ozone hole (for a maximum $\mathrm{OHA}=25 \mathrm{Mkm}^{2}$, the boundary latitude in the case of zonally symmetric ozone hole is $64.4^{\circ} \mathrm{S}$; e.g. Newman et al., 2004). This indicates that even typical QSW variability in the lower stratosphere significantly affects the vertically averaged stratospheric temperature and ozone column in the $\mathrm{SH}$ polar region, as well as ozone hole area, in late winter and early spring (Fig. 4b-e, AUG and SEP). At the polar latitudes $70^{\circ}-90^{\circ} \mathrm{S}$, the analyzed parameters $\left(\mathrm{TOC}_{\mathrm{zm}}, T_{\mathrm{zm}}, T_{\mathrm{SP}}\right.$, and $\mathrm{OHA}$ ) characterize the region of rapid ozone depletion inside the stratospheric polar vortex. As is well known, the largest ozone losses in August and September occur in the lower stratosphere at the altitudes of about $15-20 \mathrm{~km}$ where most of the ozone column normally resides and where PSCs provide reactive chlorine species for catalytic destruction 
(a)
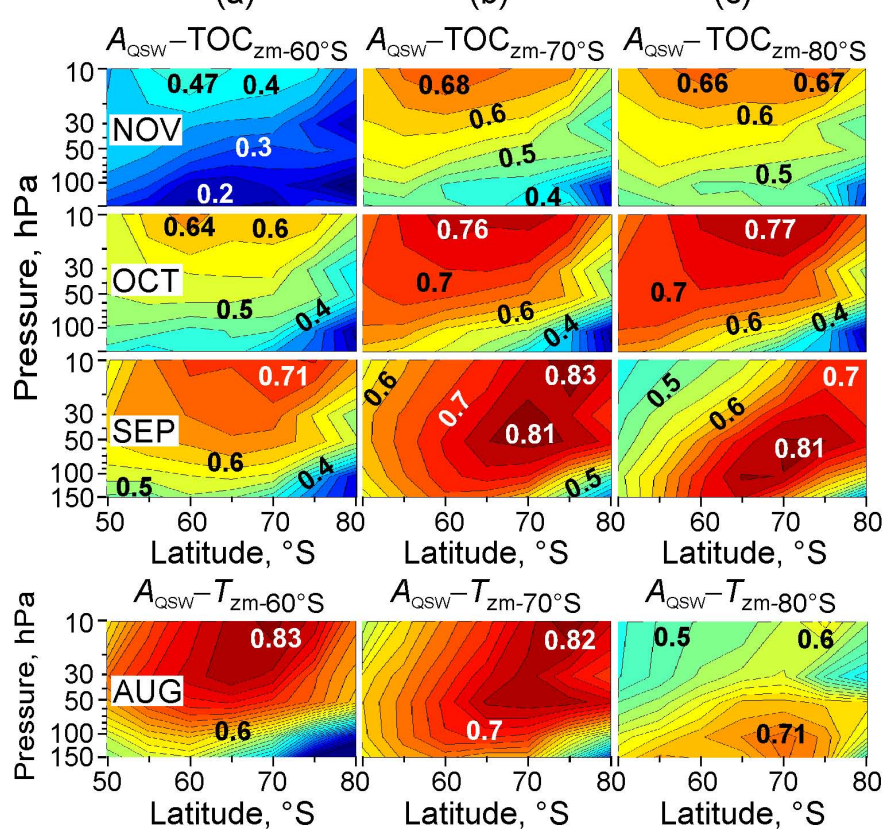

(d)

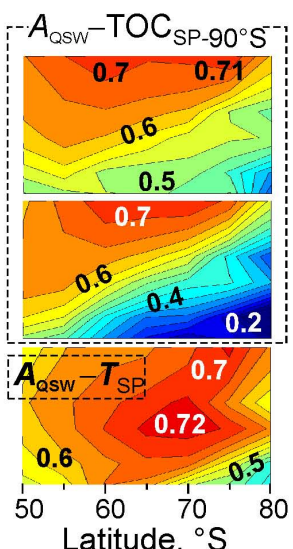

$A_{\mathrm{OSW}}-T_{\mathrm{SP}-90^{\circ} \mathrm{S}}$

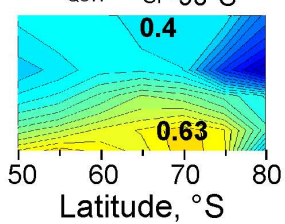

(e)
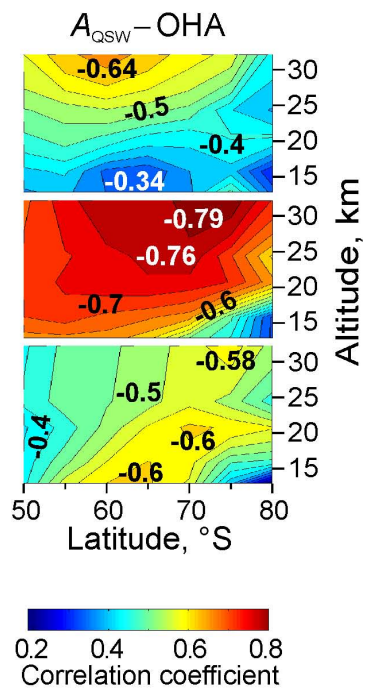

Fig. 4. Latitude-altitude distributions of the correlations between the QSW amplitude, $A_{\mathrm{QSW}}$, in August and (a-d) zonal mean stratospheric temperature, $T_{\mathrm{zm}}$, in August (AUG; $T_{\mathrm{SP}}$ on d), zonal mean total ozone, $\mathrm{TOC}_{\mathrm{zm}}$, in September (SEP), October (OCT) and November (NOV) at the latitudes $60^{\circ}-90^{\circ} \mathrm{S}$ ( $\mathrm{TOC}_{\mathrm{SP}}$ on $\mathbf{d}$ in $\mathrm{OCT}$ and NOV) and (e) ozone hole area, OHA (note the opposite sign of the correlation here).

of ozone (Salby, 1996; Randel and Wu, 1999; Lee et al., 2001; Solomon et al., 2005). Later, the ozone amount in the lower stratosphere reaches usually a minimum level in October, when the chemical ozone loss ceases (e.g. Sonkaew et al., 2011) and mid-stratospheric ozone dominates the vertical ozone profile and ozone column (Randel and Wu, 1999; Solomon et al., 2005; Tully et al., 2008; Sato et al., 2009). Therefore, the QSW impact on the ozone loss in the lower stratosphere could be a possible cause of the responses in the vertically averaged $\left(T_{\mathrm{zm}}\right)$, vertically integrated $\left(\mathrm{TOC}_{\mathrm{zm}}\right)$ or area integrated (OHA) stratospheric parameters (see Sect. 4.2 for assumed role of zonal asymmetry in this coupling).

Note that it is difficult to interpret the correlation maxima near $100-150 \mathrm{hPa}$ for $T_{\mathrm{zm}}$ at $80^{\circ} \mathrm{S}$ and $T_{\mathrm{SP}}$ (Fig. $4 \mathrm{c}$ and d, respectively, AUG) by chemical ozone loss which is negligible at these altitudes in the vortex core in August (Solomon et al., 2005; Roscoe et al., 2012). The QSW influence on temperature in the lowermost stratosphere and corresponding correlation maxima could be associated with other source of variability, potentially, including the radiative influence of Antarctica (Salby and Callaghan, 2004 and references therein). The radiative impact of the Antarctic continent leads to anomalous cooling of the lower stratosphere and would damp the positive temperature anomalies introduced by the PW activity. As seen from AUG in Fig. 4, the correlation maximum in the lower stratosphere tends to descend to $150 \mathrm{hPa}(13 \mathrm{~km})$ approaching the South Pole. This suggests the possibility of an increasing thermal influence from the cold continental troposphere below.
A common and more persistent feature of the correlation patterns in Fig. 4 is the correlation increase with altitude with maximization in the middle stratosphere near $10 \mathrm{hPa}$. To some degree, the correlation increase with altitude resembles the climatological increase of the preconditioned QSW amplitudes and their SD (Fig. 2). However, the correlation maxima at upper level in Fig. 4 are generally at the higher latitudes, except for November (Fig. 4, NOV). Both the correlation distributions in November (Fig. 4, NOV) and the $A_{\mathrm{QSW}}$ climatologies in August (Fig. 2) tend to maximize at the pressure level of $10 \mathrm{hPa}$ with the peak magnitudes near $60^{\circ} \mathrm{S}$.

The equatorward shift of the upper-level correlation maximum between September and November could be preliminarily attributed to the seasonal decrease of the polar vortex area (e.g. Waugh and Randel, 1999). In late winter, the ozone accumulation forced by the residual circulation (Andrews et al., 1987) is concentrated in ozone "collar" that circumscribes Antarctica and maximizes in the Eastern Hemisphere at $40^{\circ}-60^{\circ} \mathrm{S}$ (Salby and Callaghan, 2004). Mixing barrier near the strong polar jet axis (Holton et al., 1995; Miyazaki et al., 2005) prevents air mixing between the middle and high SH latitudes during winter and spring. Vortex area decrease during spring favours the poleward displacements of the late-winter ozone anomalies associated with the QSW anomalies. Then, ozone/temperature anomalies in the collar region fixed by $A_{\mathrm{QSW}}$ at $60^{\circ} \mathrm{S}$ in August, could be associated with the $\mathrm{TOC}_{\mathrm{zm}}$ response at higher latitudes in November (Fig. 4b-e, NOV) and appearance of the correlation maximum on each plot at $60^{\circ} \mathrm{S}$. Such persistence of an 
ozone/temperature anomaly associated with anomalous BDC transport could possible be due to a low descent rate of stratospheric air during winter and spring (1-3 km month ${ }^{-1}$; e.g. Sato et al., 2009). Correlations become lower in November $(r=0.5-0.7)$ than in September and October $(r=0.7-0.8)$ because other sources of disturbances affect the stratosphere state during spring. Nevertheless, the late-winter QSW climatology (Fig. 2) seems to be a contributing factor of the correlation maximum occurrence in the middle stratosphere in late spring (Fig. 4, NOV).

Maxima and minima relative positions in the QSW climatologies (Fig. 2) and correlations (Fig. 4) lead to the occurrence of diagonal patterns in the contour shape on both distributions. It should be noted here that these diagonal patterns resemble the vertical and meridional structure of the temperature-wave relationship studied by Salby and Callaghan (2004). They have analyzed the anomalous wintertime tendencies in the Antarctic stratosphere temperature corresponding to a $1 \mathrm{SD}$ increase in vertical component of the Eliassen-Palm (EP) flux. From Salby and Callaghan (2004), there is northward displacement of maximum coupling in the lowermost stratosphere relative to that above $30 \mathrm{hPa}\left(\sim 65^{\circ} \mathrm{S}\right.$ and $\sim 80^{\circ} \mathrm{S}$, respectively; their Fig. 11 ), similar to the correlation patterns in our Fig. 4. Salby and Callaghan (2004) suggest that the altitude-dependent radiative influence of the Antarctic continent is possible. Poleward displacement of the correlation maxima with altitude (Fig. 4) is discussed also in Sect. 4.

\section{Discussion}

In this work, we argue that the amplitude of quasi-stationary planetary waves in the stratospheric temperature distribution, $A_{\mathrm{QSW}}$, in a late winter month, August, allows for the quantitative analysis of preconditioning of ozone hole parameters in the following spring. Although the spatial resolution is not very high $(\sim 500 \mathrm{~km}$ in the meridional direction and on average $5 \mathrm{~km}$ by altitude), it seems to be sufficient for a representation of the main features of the correlation between planetary waves and ozone hole parameters (Fig. 4). In general, the wintertime PW activity is known to be positively correlated with spring polar ozone (Shindell et al., 1997; Salby and Callaghan, 2004; Weber et al., 2011) and our study accentuates the effects of the QSW component of the planetary waves in this correlation. The results (Sect. 3) indicate that the QSW amplitudes in two stratospheric layers, at $50-100 \mathrm{hPa}$ and near $10 \mathrm{hPa}$, have a certain predictive ability for the ozone hole parameters. The correlation coefficients are in the range of $0.5-0.8$ (negative in the case of the ozone hole area) and they are statistically significant at the $<1 \%$ level. The larger QSW anomalies in the lower (middle) stratosphere in August lead to larger anomalies in ozone hole parameters during August-September (August-November) with overall weakening of the ozone hole severity. We discuss below the processes that are possibly involved in this coupling.

\subsection{Seasonal tendencies}

The spring ozone dependence on wintertime planetary wave activity is generally explained by the cumulative effect of the BDC and anomalous warming of the polar vortex due to anomalous BDC (Shindell et al., 1997; Salby and Callaghan, 2004; Weber et al., 2011). The PW activity driving the BDC is usually described by the vertical component of the EP flux, which is proportional to the eddy heat flux and is a measure of the vertical PW propagation from the troposphere (when averaged over mid-latitudes or on a hemispheric scale). The EP flux into the upper stratosphere and mesosphere transmits momentum that drives a residual poleward circulation. The accompanying adiabatic warming in the downwelling air causes polar temperatures to be warmer than under conditions of radiative equilibrium.

The seasonal climatology of the QSW amplitude in the SH stratosphere differs from that of the EP flux from the troposphere. The EP flux into the SH lower stratosphere increases almost monotonically during winter and spring and reaches a maximum level in October (e.g. Randel et al., 2002). However, the seasonal tendency in the QSW amplitude in the Antarctic stratosphere is not monotonic and changes sign (from decreasing to increasing) around midwinter (Randel, 1988; Hardiman et al., 2010). The climatological amplitude of stationary waves in the SH stratosphere has maxima in June and October, and is suppressed in the late winter $\mathrm{Au}-$ gust) during the period of strongest zonal winds $\left(70-80 \mathrm{~ms}^{-1}\right.$ at $10 \mathrm{hPa}$; Hardiman et al., 2010) by the Charney-Drazin criterion (Charney and Drazin, 1961). Thus, in the seasonal climatology, the QSW amplitude increases usually from August to October and it remains at a high level in November (Randel, 1988; Hardiman et al., 2010). Consistent with this climatology, the poleward fluxes of heat and momentum in the $\mathrm{SH}$ stratosphere from the QSW1 component are weak in the winter and completely dominate the maxima during SeptemberNovember (Randel, 1988). Note that in the Arctic stratosphere, where the weaker zonal winds are more favourable for vertical wave propagation, a midwinter maximum in the QSW amplitude exists.

Based on the correlations shown in Fig. 4, our hypothesis is that variability in the late winter QSW amplitude can influence to some degree the seasonal PW amplification and, thus, the seasonal evolution of the ozone hole. In the late winter (August), at the beginning of the rapid ozone losses, the QSW amplitude and its variability are sufficiently large at the middle stratosphere altitudes (Fig. 2). Variability in the easterly momentum deposition by the QSW could influence zonal wind field setting up conditions that ultimately affect the propagation of wave energy in the spring (e.g. Shindell et al., 1997). For example, enlarged momentum deposition in August weakens the strong polar night jet and the PW 
are more able to penetrate into stratosphere by the CharneyDrazin criterion (Charney and Drazin, 1961). Weaker winds suggest also more poleward heat transport. This preconditioning related mainly to the QSW1 could contribute to the seasonal increase of the total PW activity including the higher quasi-stationary wave numbers (QSW2 and QSW3) and transient planetary waves. In such a way, the preconditioned $A_{\mathrm{QSW}}$ variability plays, to some extent, a preparatory role in further vortex evolution and could be traced in the ozone hole response up to November (Fig. 4).

The seasonal cycle of total ozone in the extratropics is closely related to the enhanced meridional ozone transport from tropical stratosphere in winter-spring due to the BDC with corresponding ozone maximum in spring in both hemispheres (Salby, 1996; Fioletov and Shepherd, 2003). In the precondition analysis for the Antarctic ozone, it is important to take into account the specific shape of the austral winter-spring half of the annual ozone cycle at high latitudes. The natural ozone cycle has been modified at high southern latitudes due to ozone hole development since the 1980s. Observations at Antarctic stations show that the spring ozone maximum no longer appears because ozone depletion starts as early as July with the following TOC minimum in September-October and ozone recovery in late November-December (Randel and Wu, 1999; Solomon et al., 2005; Shanklin et al., 2009a, b). This forms the ozone hole season which can last about half of the annual ozone cycle (July-December) since the late 1990s.

The difference between the natural and modified annual ozone cycles, as seen from comparison of the observations at the Antarctic stations in the pre-ozone hole years and ozone hole years, respectively, increases rapidly in August and September (Salby, 1996; Randel and Wu, 1999; Solomon et al., 2005). This is in accordance with typical changes in the ozone loss rate. For example, satellite measurements during 2002-2009 have shown that the ozone loss rates inside the polar vortex at the isentropic level $475 \mathrm{~K}$ (about $20 \mathrm{~km}$ ) are larger in August and September than in October, when the chemical ozone loss usually stops (Sonkaew et al., 2011).

For the polar region, we have calculated relative percent differences between monthly mean TOC in 1999-2008 and 1979-1983: $\Delta \mathrm{TOC}=\left(\mathrm{TOC}_{1999-2008}-\right.$ TOC $\left._{1979-1983}\right) \times 100 \% /$TOC$_{1979-1983}$. The MSR zonal mean data (see Sect. 2) area weighted between $70^{\circ} \mathrm{S}$ and $90^{\circ} \mathrm{S}$ were used. The first $5 \mathrm{yr}$ period includes the earliest years of the ozone hole, when the 220-DU values are sometimes only found deep in the vortex core (e.g. Newman et al., 2004). The second $10 \mathrm{yr}$ period covers the decade of the largest ozone hole area. Figure 5 shows that, indeed, this difference in the annual ozone cycles grows rapidly from July to September and decreased TOC levels exist later during October-December.

The difference change in Fig. 5 suggests that dynamical impacts during July-September can produce especially strong effects on the general severity of the ozone hole. By

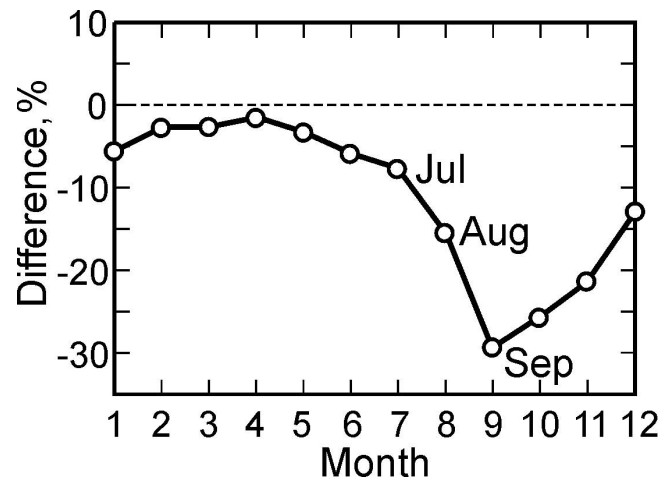

Fig. 5. Relative percent difference between monthly mean total ozone in the periods 1999-2008 and 1979-1983 averaged over the Southern polar region $\left(70^{\circ}-90^{\circ} \mathrm{S}\right)$. The zonal mean MSR data are used.

our estimate, the $A_{\mathrm{QSW}}$ variability in July exhibits the much weaker preconditioning effect than that in August (Sect. 2 and Table 1) and the responses in the stratospheric temperatures and total ozone to the mid-stratospheric QSW impact in August are observed from August until November (Fig. 4). As the most rapid ozone losses occur in the lower stratosphere during August and September, the QSW effects here are limited by these two months (Sect. 3 and Fig. 4b-e, AUG and SEP).

Hence, the preconditioning effects related the QSW activity differ somewhat in timing and duration from those in total tropospheric wave forcing of the $\mathrm{SH}$ polar stratosphere in winter (Shindell et al., 1997; Salby and Calaghan, 2004; Weber et al., 2011). This seems to be associated with combination of the specific seasonal cycles in the QSW activity and ozone loss rate which suggest the late-winter modification of the ozone hole evolution.

\subsection{Zonal asymmetry}

It is known that a climatological east-west asymmetry of the Antarctic polar vortex and ozone hole exists with a typical displacement from the South Pole toward the Atlantic sector, $0^{\circ}-60^{\circ} \mathrm{W}$ (Wirth, 1993; Waugh and Randel, 1999; Grytsai et al., 2007; Agosta and Canziani, 2011). Figure 6 illustrates the changes in the TOC field asymmetry in August under conditions of the strong polar vortex in 2006 (Fig. 6a) and the weak polar vortex in 2002 (Fig. 6b). The MSR images are used (Sect. 2). As noted in Sect. 2, these two years represent a range of dynamical variability in wave-ozone coupling in the Antarctic stratosphere (Weber et al., 2011). The largest changes in the ozone field in 2002 occur between about $90^{\circ} \mathrm{E}$ and $240^{\circ} \mathrm{E}$ (Fig. 6b) as a result of the maximum ozone accumulation due to the BDC which tend to be zonally asymmetric in the SH stratosphere (Salby and Callaghan, 2004; Sato et al., 2009; Gabriel et al., 2011). The TOC minimum between about $0^{\circ} \mathrm{E}$ and $60^{\circ} \mathrm{W}$ (Fig. $6 \mathrm{~b}$ ) is the area 


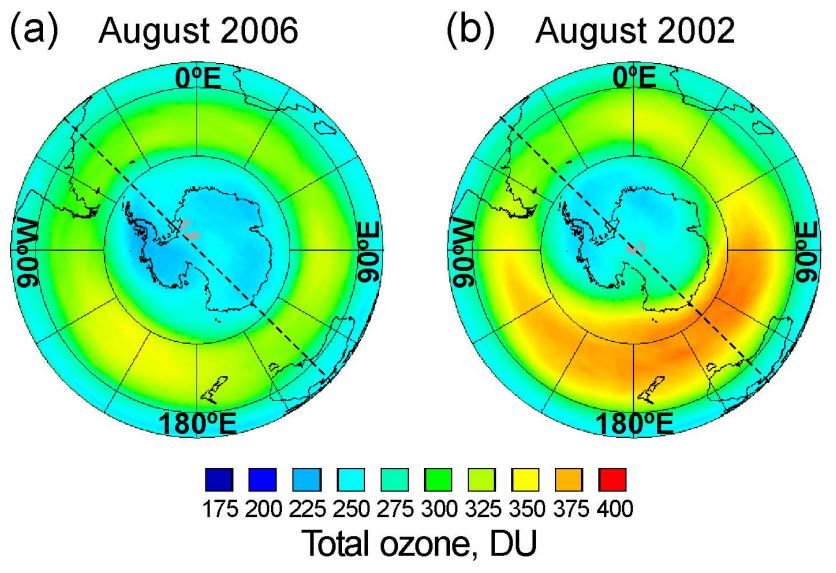

Fig. 6. Total ozone fields from Multi Sensor Reanalysis data for (a) strong and zonally symmetric vortex in August 2006 and (b) weak and zonally asymmetric vortex in August 2002.

of almost undisturbed TOC level in comparison with that in 2006 (Fig. 6a).

We have compared the meridional temperature profiles for August 2002 and August 2006 at the two pressure levels, $10 \mathrm{hPa}$ and $50 \mathrm{hPa}$ (Fig. 7a and b, respectively) using NCEPNCAR reanalysis data. These pressure levels correspond to the strongest correlation peaks $(r=0.8)$ in the $A_{\mathrm{QSW}}-T_{\mathrm{zm}}$ relationships for August (Fig. 4, AUG). The asymmetry axis (longitudes of the temperature minimum and maximum) was taken in the meridional direction $45^{\circ} \mathrm{W}-135^{\circ} \mathrm{E}$ (dashed lines in Fig. 6). This differs from the asymmetry axis about $0^{\circ}-$ $180^{\circ} \mathrm{E}$ in the $100 \mathrm{hPa}$ temperatures in Fig. 1 because of westward tilt of the QSW phase with altitude (Randel, 1988; Gabriel et al., 2011). Temperature fields (not shown) indicate also that the TOC maximum between $90^{\circ} \mathrm{E}$ and $180^{\circ} \mathrm{E}$ in Fig. $6 \mathrm{~b}$ is associated with the $10-\mathrm{hPa}$ temperature maximum within this sector, i.e. to the west of the 100-hPa temperature maximum around $180^{\circ} \mathrm{E}$ (Fig. 1).

Figure 7 shows the low zonal asymmetry in August 2006 (dashed curves) and high zonal asymmetry in August 2002 (solid curves) in agreement with Fig. 6. The changes in the temperature profiles in 2002 are mainly due to a temperature increase over the Eastern Hemisphere $\left(135^{\circ} \mathrm{E}\right.$, right half of the solid curves). These changes are accompanied by the poleward shift of the meridional temperature gradients here. Over the Western Hemisphere $\left(45^{\circ} \mathrm{W}\right.$, left half of the plots), the temperature profiles are not significantly different. This means the zonally averaged temperature variations are mainly dependent on their variability over the eastern longitudes. Such an asymmetric contribution to zonal mean temperature variability is obviously related to the asymmetric ozone accumulation (Fig. 6) due to asymmetries in the residual circulation as noted above.
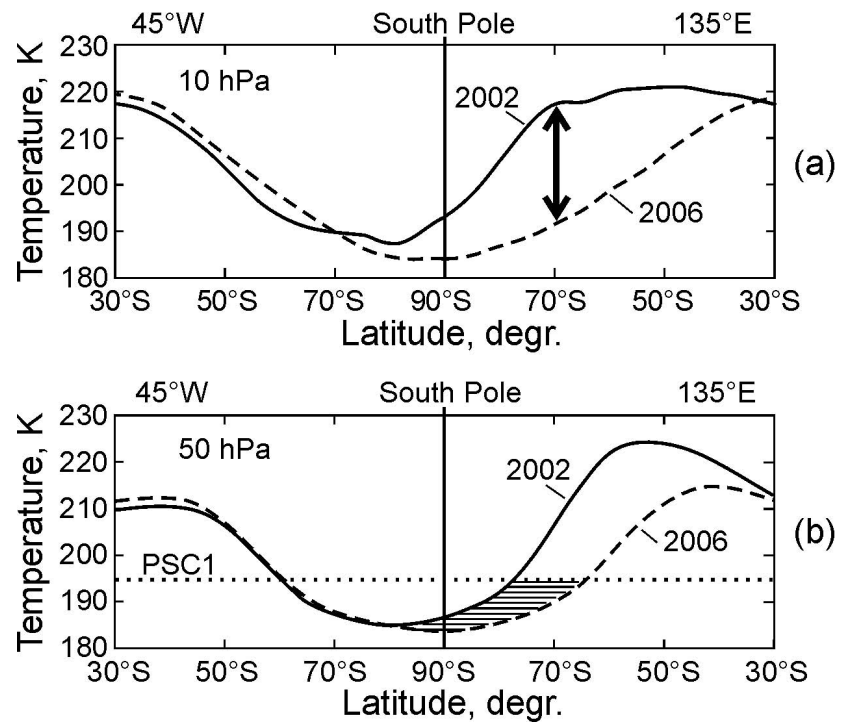

Fig. 7. Stratospheric temperature profiles in the meridional plane $45^{\circ} \mathrm{W}-135^{\circ} \mathrm{E}$ at the pressure levels of (a) $10 \mathrm{hPa}$ and (b) $50 \mathrm{hPa}$ for August 2002 (large vortex asymmetry, solid curves) and August 2006 (small vortex asymmetry, dashed curves).

From Salby and Callaghan (2004), the interannual changes of the wintertime tendency in the $50 \mathrm{hPa}$ geopotential height related to the changes in the vertical component of the EP flux show similar asymmetric patterns with a maximum response in geopotential height seen in the Eastern Hemisphere. This maximum is located at higher latitudes (with the steepest meridional gradient poleward of $60^{\circ} \mathrm{S}$ ) in winters of strong PW activity than in winters of weak PW activity (Salby and Callaghan, 2004; their Fig. 13); the latitudinal changes in response at opposite longitudes in the Western Hemisphere are insignificant. Taking into account the climatology (east-west asymmetry in the ozone accumulation), the ozone/temperature changes in the west segment of the Antarctic stratosphere do not contribute significantly to changes in the zonal means. It seems that the positive correlation in Fig. 4 (AUG) is mainly due to direct proportionality between interannual temperature variations in the east segment of the Antarctic stratosphere and the zonal mean temperatures.

It should be noted that the zonal mean meridional ozone flux in the SH polar region is typically low over the whole year except for a peak in October and November (Miyazaki et al., 2005; Monier and Weare, 2011). Similarly, Figs. 6 and 7 suggest that the changes in the zonal means consist of a relatively small component independent of the changes in the asymmetric ozone accumulation. The latter relates to the vertical component of the eddy ozone flux (Miyazaki and Iwasaki, 2005) and is in agreement with observed zonal asymmetry in the vertical velocity in the Antarctic stratosphere (Sato et al., 2009; Gabriel et al., 2011). 
An important consequence of the asymmetric temperature increase in 2002 (Fig. 7, solid curves) is the noticeable poleward shift of the meridional temperature gradients in the Eastern Hemisphere. The gradient is less shifted but is steeper in the lower stratosphere $(50 \mathrm{hPa}$, Fig. $7 \mathrm{~b})$ than in the middle stratosphere (10 hPa, Fig. 7a). In the lower stratosphere, as seen from the hatched area below the PSC threshold (dotted line in Fig. 7b), the poleward shift of the temperature gradient could be the main cause of the PSC area decrease in August 2002 in comparison with August 2006.

Similar asymmetric changes in the August ozone/temperature fields (not shown) occur always in the weak polar vortex regime $(1988,2002,2004,2007$ and 2010) relative to the strong polar vortex regime $(1996,2001,2003$, 2006 and 2011; see, for example, the TOC fields from the MSR data at http://www.temis.nl/protocols/O3global.html) in general consistency with the results by Salby and Callaghan (2004). Since the western part of the meridional temperature profile is usually less variable (Fig. 7), the interannual temperature variability near $70^{\circ} \mathrm{S}$ in its eastern part could give the largest contribution to the asymmetric, temperature-dependent PSC occurrence. The asymmetric PSC area variations, in turn, result in the related ozone loss and temperature variations (e.g. Gabriel et al., 2011, who assume that the feedback of temperature-dependent chemistry could enhance the amplitudes of the stationary wave patterns in ozone in the case of a zonally asymmetric configuration of the cold winter polar vortex).

It is possible that the asymmetry variability in the lower stratosphere affects the threshold temperatures for the PSC formation and results in irreversible, latitude-dependent changes of the PSC volume. In Fig. 7b, this influence is seen at the latitudes $\sim 70^{\circ}-80^{\circ} \mathrm{S}$ (dashed area latitudes nearby the dotted threshold line) and it could be expanded toward the pole by high air mixing inside the Antarctic polar vortex $\left(70^{\circ}-90^{\circ} \mathrm{S}\right.$, e.g. Lee et al., 2001). Presence of the correlation maximum in the lower stratosphere in the responses of the zonal means between the latitudes $70^{\circ} \mathrm{S}$ and $90^{\circ} \mathrm{S}$ (Fig. 4b-d, AUG and SEP) and of ozone hole area (Fig. 4e, SEP), as well as its absence at $60^{\circ} \mathrm{S}$ (Fig. 4a) is consistent with this assumption. Close latitudes of this correlation maximum in August and September (around $70^{\circ}$ S; Fig. 4b-e, AUG and SEP) suggest that the ozone field in September is under influence of preconditioned modification by the QSW induced asymmetry. Note that absence of such modification in August 2006 (Figs. 6a and 7, dashed curves) favoured the Antarctic vortex concentricity and longer air exposure at the lower temperatures at the inner vortex edge (e.g. Maturilli et al., 2005 and references therein) that resulted both in larger PSC area in late winter and in larger net ozone loss in spring.

At the upper levels $(\sim 30 \mathrm{~km})$, the PSC do not affect the ozone/temperature variability (e.g. Sonkaew et al., 2011). However, the large poleward shift of the temperature gradient at $135^{\circ} \mathrm{E}$ indicates the higher temperature change again near $70^{\circ} \mathrm{S}$ (double arrow in Fig. 7a). Such asymmetric changes provide a large contribution to the vertically averaged temperatures, as well as to their zonal means that could be a possible explanation of the correlation maximum occurrence at the upper level near $70^{\circ} \mathrm{S}$ too (Fig. 4, AUG).

Generally, the larger QSW disturbances suggest a larger poleward shift of the meridional ozone/temperature gradients in the Eastern Hemisphere stratosphere (Figs. 6 and 7). In the vertical, this can result in the stronger response of the zonal means to the $A_{\mathrm{QSW}}$ variations further poleward in middle stratosphere (Fig. 7a) than in lower stratosphere (Fig. 7b). Such tendency could contribute to a diagonal pattern in the correlation distribution (Fig. 4) in addition to possible radiative influence of Antarctica (Sect. 3).

To some extent, such a tendency is seen from the maximum in the $A_{\mathrm{QSW}}$ variability (Fig. $2 \mathrm{~b}$ ) which exhibits some poleward extension relative to that of $A_{\mathrm{QSW}}$ itself (Fig. 2a) as noted in Sect. 2. It is possibly related to the properties of the east-west asymmetry in the Antarctic vortex variability noted above and its vertical change illustrated partly by Fig. 7. With the 5-degree resolution by latitude in this work, the QSW-induced disturbances around $70^{\circ} \mathrm{S}$ (i.e. poleward of the vortex edge) are good indicators of the variability in the zonal means over the latitudes $60^{\circ}-90^{\circ} \mathrm{S}$ (Fig. $4 \mathrm{a}-\mathrm{d}$ ) and in the ozone hole area (Fig. 4e).

Seasonal persistence in the correlations until November (Fig. 4) as noted in Sect. 4.1 can be related to variations in the momentum deposition by the QSW in late winter that could influence the vortex strength and following seasonal amplification of the PW activity. Additional source of the preconditioned vortex weakening could be associated with the asymmetric ozone heating in the stratosphere by the asymmetric BDC. Asymmetric enhancement of the ozone accumulation (Fig. 6) and related ozone heating of the stratosphere (Fig. 7) lead to increase of the zonal mean temperatures in the vortex edge and sub-vortex regions. We noted above that, under the low zonal mean ozone transport, the changes in the eddy vertical ozone flux associated with the asymmetric BDC (Miyazaki and Iwasaki, 2005; Monier and Weare, 2011; Gabriel et al., 2011) contribute largely to the changes in the zonal mean ozone and temperature in the late austral winter. This can result in the changes of the equatorward temperature gradient and, through thermal wind balance (Salby, 1996), in the strength of the polar night jet. This assumption is consistent with the asymmetric ozone accumulation effects in the zonal wind asymmetry: weaker (stronger) winds are observed at the longitudes of the ozone maximum (minimum) as shown by Grytsai et al. (2008).

Thus, tropospheric PW activity in late austral winter can contribute to the Antarctic polar vortex weakening (i) through the easterly momentum deposition by the QSW component which reaches the maximum amplitudes in middle stratosphere and (ii) through change of the pole-equator temperature difference by contribution to zonal mean temperature increase from the asymmetric ozone heating. Both preconditioning sources can have effects on the seasonal time 
scale, because of modification of the seasonal tendencies (Sect. 4.1) and increasing interaction between zonal wind, PW penetration into stratosphere and polar vortex strength during late winter and spring. In addition to vortex weakening, seasonal vortex area decrease could contribute to the latitude-altitude distribution of the correlations and their changes in Fig. 4 as assumed in Sect. 3.

The QSW-related influences on the seasonal evolution of the Antarctic polar vortex and ozone hole are in general agreement with the effects of the zonally asymmetric ozone in model studies (McCormack et al., 2011; Albers and Nathan, 2012) which have found significant differences in winter extratropical stratospheric temperatures depending on the presence or absence of zonally asymmetric ozone (ZAO) heating. From Albers and Nathan (2012), ZAO contributes to zonal wind via planetary wave drag (their pathway 1 ) and via zonal mean ozone heating (pathway 2). In their numerical experiment based on coupled equations for wind, temperature and ozone, ZAO causes a slightly weaker and warmer vortex in the dynamically controlled region, below $\sim 35 \mathrm{~km}$. The authors note that the model can underestimate the impact of pathway 2 on the zonal mean circulation. According to McCormack et al. (2011), significantly warmer and weaker stratospheric polar vortex in winter is possible in the simulations including zonally asymmetric ozone heating.

The PW propagation into Antarctic stratosphere in the late austral winter is damped, nevertheless variability in its QSW component suggests high positive coupling between zonal asymmetry and zonal means over the latitude range $60^{\circ}-$ $90^{\circ} \mathrm{S}$ (Fig. 4, AUG). Climatological east-west asymmetry in the Antarctic stratosphere and low zonal mean ozone transport, as noted above, lead to strong dependence of the zonal mean ozone heating on the eddy vertical ozone flux associated with zonally asymmetric residual circulation. This agrees with the results of Salby and Callaghan (2004) who have shown that the BDC-related tendency of asymmetric ozone increase in austral winter is accompanied by positive anomalies in zonal mean temperature in the stratosphere (their Figs. 17 and 18). It seems that the dynamical disturbances by the QSW1 type produce co-variability of zonally asymmetric and zonal mean ozone heating in the late-winter Antarctic stratosphere which, by the TOC and temperature data, affects the ozone hole until November (Fig. 4). Further examinations of these effects using other data sources and models are necessary. Seasonal persistence of the QSW impact in Fig. 4 suggests that the ZAO effect in the late winter SH stratosphere is important even under generally low wave activity and strong polar jet. Modification of wave propagation versus wave damping (by easterly momentum deposition and asymmetric ozone heating, as noted above, or via pathway 1 and 2, respectively, by Albers and Nathan, 2012) could be considered with respect to modulation of the vortex strength and temperature on seasonal time scale.

\subsection{Ozone mixing effects}

In late winter, meridional transport and eddy mixing in the Antarctic stratosphere are negligible due to the mixing barrier near the strong polar night jet (Andrews et al., 1987; Holton et al., 1995; Miyazaki et al., 2005) as noted above. Erosion of the polar vortex by PW breaking starts earlier in the middle stratosphere than that in the lower stratosphere (Waugh and Randel, 1999). The horizontal diffusion coefficient for ozone mixing in the Antarctic stratosphere at $20 \mathrm{hPa}$ increases at the high latitudes $\left(60^{\circ}-90^{\circ} \mathrm{S}\right)$ since October and maximizes in November-December (Miyazaki et al., 2005; their Fig. 7). At the same time, in the lower stratosphere, the mixing barrier at the Antarctic vortex edge exists until the end of November without either further chemical loss or any significant dilution by transport across the vortex edge, even after anomalously strong wave disturbances such as those in spring 2002 (e.g. Konopka et al., 2005). Strong vertical differentiation in ozone amount in lower and middle stratosphere exists until polar vortex breaks down in late November-December.

The seasonal change in the ozone amount in the lower stratosphere related to chemical ozone destruction (Fig. 5) results in an insignificant contribution to ozone column variability in October and November in comparison with the mid-stratospheric ozone as noted in Sect. 3. The correlation maximum associated with the late-winter QSW influence in the middle stratosphere dominates the correlation patterns in Fig. 4 and is only below statistical significance in the $T_{\mathrm{SP}}$ response in August (Fig. 4d, AUG). As could be inferred from Figs. 6 and 7, asymmetry variations in August suggest relatively low contribution to ozone/temperature changes over the South Pole (in agreement with the $A_{\mathrm{QSW}}$ climatology in Fig. 2 which indicates significant poleward decrease of the asymmetry). Nevertheless, transition from August to September (Fig. 4d, SEP) is marked by strong increase in the $T_{\mathrm{SP}}$ response $(r=0.7)$ to the same late-winter disturbances by the QSW not only in the middle stratosphere but also in the lower stratosphere. Using a very close similarity between the correlation patterns in Fig. 4b-e (SEP) and Fig. 4b (AUG) it could be assumed that the latter (the $T_{\mathrm{zm}}$ response at $70^{\circ} \mathrm{S}$ in August) determines to a large degree the relationships for the ozone hole parameters in September.

As discussed in Sect. 4.2, the QSW amplitude near $70^{\circ} \mathrm{S}$ may be tightly coupled with the PSC threshold temperature in the lower stratosphere and related ozone losses here. Ozone depletion in the ozone hole grows rapidly from July to September (Fig. 5) starting near the vortex edge, $60^{\circ}-70^{\circ} \mathrm{S}$ (e.g. Lee et al., 2001). Strong air mixing inside the Antarctic polar vortex $\left(70^{\circ}-90^{\circ} \mathrm{S}\right.$; Lee et al., 2001) can expand the ozone loss anomalies induced by the QSW near $70^{\circ} \mathrm{S}$ in August over the ozone hole region in September contributing to enhancement of the correlation maximum near $50 \mathrm{hPa}$ (Fig. 4b-e, SEP). Over the South Pole, the correlation increase in September to upper-level QSW could be caused 
by the decrease in vortex area which starts as early as August at this level and is faster than in the lower stratosphere (Waugh and Randel, 1999). This tendency could favour poleward displacements of the mid-latitude ozone accumulation anomalies, without irreversible mixing. In combination with typically larger displacements of the polar vortex edge in the middle stratosphere than in the lower stratosphere (Fig. 7), the mid-stratospheric part of the vertical ozone profile may cause strong variability of the total ozone column.

For example, according to Kondragunta et al. (2005), in the case of the 2002 ozone hole, the offset between the vortices in the lower stratosphere and middle stratosphere masked the ozone depletion in the lower stratosphere and resulted in higher total ozone column and a smaller ozone hole size estimate. According to Tully et al. (2008), a progressive poleward shift with increasing altitude is seen in the Eastern Hemisphere ozone maximum in September 2007 (their Fig. 33). It is possible that the preconditioned QSW influence on the seasonal PW amplification can contribute to increasing the amplitude of the meridional displacements of the Antarctic vortex edge and adjacent ozone collar.

Additionally, the poleward eddy transport by PW breaking (Andrews et al., 1987) compensates for the chemical ozone losses in the lower stratosphere and provides an important contribution to the total column during the recovery phase of the ozone hole. Observations at the Antarctic stations Syowa and Davis located in the Eastern Hemisphere near $70^{\circ} \mathrm{S}\left(40^{\circ} \mathrm{E}\right.$ and $78^{\circ} \mathrm{E}$, respectively) show that ozone maximum at $20-25 \mathrm{~km}$ in the vertical ozone profile in the spring can exceed that at $15-20 \mathrm{~km}$ in the undisturbed winter profile (Sato et al., 2009, their Fig. 2; Tully at al., 2008, their Figs. 20-22). Because the typical ozone maximum at $15-20 \mathrm{~km}$ disappears almost completely in the spring ozone hole, the upper-level ozone becomes the main contributor to column ozone variability as emphasized above.

It should be noted that ozone mixing in the middle stratosphere depends not only on wave breaking activity but also on the meridional ozone gradient and is strongly related to the evolution of the polar night jet (Miyazaki et al., 2005). Late winter variability of the gradients in the total ozone fields (Fig. 6) and in the meridional temperature profiles at $10 \mathrm{hPa}$ (Fig. 7a) suggests their possible preconditioning role for strengthening horizontal ozone mixing in the middle stratosphere in spring. As spring progresses, the influence exerted on the meridional gradients by the QSW in August could contribute to the stronger eddy mixing (correlation maximum near $10 \mathrm{hPa}$ in Fig. 4). Overall, in the upper levels of the ozone hole, the QSW controls in-fill, while in the lower levels it limits the overall amount of chemical loss and the size of the ozone depleted area and, thus, contributes to the correlation patterns in Fig. 4.

Summarizing, multiple individual factors are likely involved in producing the spring total ozone response to the late-winter QSW disturbances in the stratosphere. The lowerstratospheric correlation maximum (Fig. 4b-e, AUG and
SEP) could be mainly associated with dependence of the ozone losses on the variations of the PSC threshold temperature at the poleward side of the polar vortex edge (near $70^{\circ} \mathrm{S}$ ). In the lowermost stratosphere (Fig. $4 \mathrm{c}$ and d, AUG), the radiative influence of the Antarctic continent is possible. Correlation peak occurrences in the middle stratosphere (Fig. 4), their seasonal persistence and changes by value and latitude of the correlation maxima suggest their link with (i) late-winter QSW climatology, (ii) polar vortex warming and weakening due to heat and easterly momentum deposition and pole-equator temperature difference modification by the QSW, (iii) influence of the meridional temperature gradient at the vortex edge on the horizontal ozone mixing, (iv) seasonal decrease of the polar vortex area and (v) altitude and longitude dependent, meridional displacements of the vortex edge due to QSW1 dominance. The QSW1 dominance and related ozone/temperature zonal asymmetry seem to be a general underlying circumstance of the preconditioned modification of the Antarctic stratosphere with its seasonal time scale effects.

\section{Conclusions}

Analysis of the relationships between the QSW amplitudes in the late austral winter (August) and the ozone hole characteristics (zonal mean total ozone, vertically averaged zonal mean stratospheric temperatures and the ozone hole area) in austral spring (September-November) was carried out. The temperature (NCEP-NCAR Reanalysis) and total ozone (TOMS/OMI, Multi Sensor Reanalysis and Amundsen-Scott station) data were used. Linear correlation coefficients (maximum $r=0.83$ ) show significant positive coupling (negative for the ozone hole area) between the analyzed time series over the 1985-2010 period, the principal years of the Antarctic ozone hole. The winter-time planetary wave activity is known to be positively correlated with spring polar ozone and the correlation patterns in our results reveal for the first time different preconditioning influences of QSW variability in the lower and middle stratosphere on spring total ozone.

Quasi-stationary wave number one is the dominant component of the planetary waves penetrating into the Antarctic stratosphere, suggesting the involvement of zonal asymmetry in the preconditioning. In the late winter, the climatological east-west asymmetry of the Antarctic polar vortex due to QSW1 is accompanied by zonal asymmetry in the residual large-scale ozone transport which forms asymmetric ozone and temperature fields and asymmetric meridional gradients at the vortex edge. Variability in the eddy vertical ozone flux and related asymmetric ozone accumulation and heating is assumed to be main modifying factor for the zonal mean ozone and temperature in the late winter.

In the lower stratosphere, by our qualitative estimate, the direct eddy-zonal mean temperature coupling could affect the threshold temperature for the PSC formation and resulted 
ozone losses. In agreement with presented seasonal tendency in total ozone, this coupling could explain the latitudinal location of the correlation maxima in August and September related to the lower-stratospheric QSW. However, a more complete statistical analysis is necessary to confirm both this interpretation and possibility of the effects associated with the radiative influence of the Antarctica in the lowermost stratosphere.

It is interesting that the late-winter temperature anomalies near $10 \mathrm{hPa}$ fixed by the QSW amplitude variations can influence the Antarctic stratosphere until November. We have noted several related processes participating possibly in such persistent effect: direct coupling between eddy and zonal mean temperature modifying the pole-equator temperature difference and, through thermal wind balance, vortex strength; vortex warming and weakening due to heat and easterly momentum deposition by the QSW; influence of the meridional temperature gradients on the strength of horizontal ozone mixing; seasonal tendencies in the QSW amplification, ozone depletion-accumulation-mixing and polar vortex structure.

The preconditioning indicator, the QSW amplitude, and the ozone hole evolution are altitude and latitude dependent in the dynamically controlled stratosphere and many details of their coupling are not represented in this work. Additional information could be obtained using: better spatial resolution with vertically resolved ozone and temperature; other parameters (in context of zonal asymmetry), such as zonal wind, geopotential height, tropopause height, potential vorticity, horizontal ozone mixing and the QSW phase; model analysis to estimate relative contribution of chemistry and dynamics, transport and mixing to the late-winter QSW modification of the Antarctic stratosphere and to seasonal persistence of this influence.

Acknowledgements. NCEP Reanalysis data provided by the NOAA/OAR/ESRL PSD, Boulder, Colorado, USA, from their Web site at http://www.esrl.noaa.gov/psd/. TOMS/OMI data have been obtained from the NASA Web site at http://ozoneaq.gsfc.nasa.gov. The total ozone Multi Sensor reanalysis data provided by the ESA TEMIS project at the KNMI Web site http://www.temis.nl/protocols/o3field/o3mean_msr.php. The authors thank two anonymous referees for detailed comments and useful suggestions. The authors would like to thank Lon Hood of the University of Arizona for reading the manuscript and useful advice. The work was supported in part by Kyiv National Taras Shevchenko University, project 11BF051-01 and Australian Antarctic Science project 737.

Edited by: A. J. G. Baumgaertner

\section{References}

Agosta, E. A. and Canziani, P. O.: Austral spring stratospheric and tropospheric circulation interannual variability, J. Climate, 24, 2629-2647, doi:10.1175/2010JCLI3418.1, 2011.

Albers, J. R. and Nathan, T. R.: Pathways for communicating the effects of stratospheric ozone to the polar vortex: role of zonally asymmetric ozone, J. Atmos. Sci., 69, 785-801, doi:10.1175/JAS-D-11-0126.1, 2012.

Allen, D. R., Bevilacqua, R. M., Nedoluha, G. E., Randall, C. E., and Manney, G. L.: Unusual stratospheric transport and mixing during the 2002 Antarctic winter, Geophys. Res. Lett., 30, 1599, doi:10.1029/2003GL017117, 2003.

Andrews, D. G., Holton, J. R., and Leovy, C. B.: Middle Atmosphere Dynamics, International Geophysical Series, 40, Academic Press, 489 pp., 1987.

Canziani, P. O., Malanca, F. E., and Agosta, E. A.: Ozone and upper troposphere/lower stratosphere variability and change at southern midlatitudes 1980-2000: Decadal variations, J. Geophys. Res., 113, D20101, doi:10.1029/2007JD009303, 2008.

Charney, J. G. and Drazin, P. G.: Propagation of planetary-scale disturbances from the lower into the upper atmosphere, J. Geophys. Res., 66, 83-109, doi:10.1029/JZ066i001p00083, 1961.

Ciasto, L. M. and Thompson, D. W. J.: Observations of largescale ocean-atmosphere interaction in the Southern Hemisphere, J. Climate, 21, 1244-1259, doi:10.1175/2007JCLI1809.1, 2008.

Crook, J. A., Gillett, N. P., and Keeley, S. P. E.: Sensitivity of Southern Hemisphere climate to zonal asymmetry in ozone, Geophys. Res. Lett., 35, L07806, doi:10.1029/2007GL032698, 2008.

Dobber, M., Kleipool, Q., Dirksen, R., Levelt, P., Jaross, G., Taylor, S., Kelly, T., Flynn, L., Leppelmeier, G., and Rozemeijer, N.: Validation of Ozone Monitoring Instrument level 1b data products, J. Geophys. Res., 113, D15S06, doi:10.1029/2007JD008665, 2008.

Fioletov, V. E. and Shepherd, T. G.: Seasonal persistence of midlatitude total ozone anomalies, Geophys. Res. Lett., 30, 1417, doi:10.1029/2002GL016739, 2003.

Gabriel, A., Körnich, H., Lossow, S., Peters, D. H. W., Urban, J., and Murtagh, D.: Zonal asymmetries in middle atmospheric ozone and water vapour derived from Odin satellite data 20012010, Atmos. Chem. Phys., 11, 9865-9885, doi:10.5194/acp-119865-2011, 2011.

Grytsai, A. V., Evtushevsky, O. M., Agapitov, O. V., Klekociuk, A. R., and Milinevsky, G. P.: Structure and long-term change in the zonal asymmetry in Antarctic total ozone during spring, Ann. Geophys., 25, 361-374, 2007, http://www.ann-geophys.net/25/361/2007/.

Grytsai, A. V., Evtushevsky, O. M., and Milinevsky, G. P.: Anomalous quasi-stationary planetary waves over the Antarctic region in 1988 and 2002, Ann. Geophys., 26, 1101-1108, 2008, http://www.ann-geophys.net/26/1101/2008/.

Hardiman, S. C., Butchart, N., Osprey, S. M., Gray, L. J., Bushell, A. C., and Hinton, T. J.: The climatology of the middle atmosphere in a vertically extended version of the Met Office's climate model. Part I: Mean state, J. Atmos. Sci., 67, 1509-1525, doi:10.1175/2009JAS3337.1, 2010.

Holton, J. R., Haynes, P. H., McIntyre, M. E., Douglas, A. R., Rood, R. B., and Pfister, L.: Stratosphere-troposphere exchange, Rev. Geophys., 33, 403-439, 1995.

Hood, L. L. and Soukharev, B. E.: Interannual variations of total 
ozone at northern midlatitudes correlated with stratospheric EP flux and potential vorticity, J. Atmos. Sci., 62, 3724-3740, 2005.

Huck, P. E., McDonald, A. J., Bodeker, G. E., and Struthers, H.: Interannual variability in Antarctic ozone depletion controlled by planetary waves and polar temperature, Geophys. Res. Lett., 32, L13819, doi:10.1029/2005GL022943, 2005.

Kalnay, E., Kanamitsu, M., Kistler, R., Collins, W., Deaven, D., Gandin, L., Iredell, M., Saha, S., White, G., Woollen, J., Zhu, Y., Leetmaa, A., Reynolds, R., Chelliah, M., Ebisuzaki, W., Higgins, W., Janowiak, J., Mo, K. C., Ropelewski, C., Wang, J., Jenne, R., and Joseph, D.: The NCEP/NCAR 40-Year Reanalysis Project, B. Am. Meteorol. Soc., 77, 437-471, 1996.

Karpetchko, A., Kyrö, E., and Knudsen, B. M.: Arctic and Antarctic polar vortices 1957-2002 as seen from the ERA-40 reanalyses, J. Geophys. Res., 110, D21109, doi:10.1029/2005JD006113, 2005.

Kawa, S. R., Newman, P. A., Stolarski, R. S., and Bevilacqua, R. M.: Fall vortex ozone as a predictor of springtime total ozone at high northern latitudes, Atmos. Chem. Phys., 5, 1655-1663, doi:10.5194/acp-5-1655-2005, 2005.

Kondragunta, S., Flynn, L. E., Neuendorffer, A., Miller, A. J., Long, C., Nagatani, R., Zhou, S., Beck, T., Beach, E., McPeters, R., Stolarski, R., Bhartia, P. K., Deland, M. T., and Huang, L.-K.: Vertical structure of the anomalous 2002 Antarctic ozone hole, J. Atmos. Sci., 62, 801-811, 2005.

Konopka, P., Grooss, J.-U., Hoppel, K. W., Steinhorst, H.-M., and Müller, R.: Mixing and chemical ozone loss during and after the Antarctic polar vortex major warming in September 2002, J. Atmos. Sci., 62, 848-859, 2005.

Lee, A. M., Roscoe, H. K., Jones, A. E., Haynes, P. H., Shuckburgh, E. F., Morrey, M. W., and Pumphrey, H. C.: The impact of the mixing properties within the Antarctic stratospheric vortex on the ozone loss in spring, J. Geophys. Res., 106, 3203-3211, 2001.

Matsuno, T.: Vertical propagation of stationary planetary waves in the winter Northern Hemisphere, J. Atmos. Sci., 27, 871-883, 1970.

Maturilli, M., Neuber, R., Massoli, P., Cairo, F., Adriani, A., Moriconi, M. L., and Di Donfrancesco, G.: Differences in Arctic and Antarctic PSC occurrence as observed by lidar in Ny-Ålesund $\left(79^{\circ} \mathrm{N}, 12^{\circ} \mathrm{E}\right)$ and McMurdo $\left(78^{\circ} \mathrm{S}, 167^{\circ} \mathrm{E}\right)$, Atmos. Chem. Phys., 5, 2081-2090, doi:10.5194/acp-5-2081-2005, 2005.

McCormack, J. P., Nathan, T. R., and Cordero, E. C.: The effect of zonally asymmetric ozone heating on the Northern Hemisphere winter polar stratosphere, Geophys. Res. Lett., 38, L03802, doi:10.1029/2010GL045937, 2011.

McPeters, R. D., Krueger, A. J., Bhartia, P. K., Herman, J. R., Schlesinger, B., Wellemeyer, C. G., Seftor, C. J., Jaross, G., Taylor, S. L., Swissler, T., Torres, O., Labow, G., Byerly, W., and Cebula, R. P.: Nimbus-7 Total Ozone Mapping Spectrometer (TOMS) Data Products User's Guide, NASA Reference Publication 1384, 73 pp., 1996.

McPeters, R. D., Bhartia, P. K., Krueger, A. J., Herman, J. R., Wellemeyer, C. G., Seftor, C. J., Jaross, G., Torres, O., Moy, L., Labow, G., Byerly, W., Taylor, S. L., Swissler, T., and Cebula, R. P.: Earth Probe Total Ozone Mapping Spectrometer (TOMS) Data Products User's Guide, NASA Reference Publication 1998206895, 70 pp., 1998.

Miyazaki, K. and Iwasaki, T.: Diagnosis of meridional ozone transport based on mass-weighted isentropic zonal means, J. Atmos. Sci., 62, 1192-1208, 2005.
Miyazaki, K., Iwasaki, T., Shibata, K., and Deushi, M.: Roles of transport in the seasonal variation of the total ozone amount, J. Geophys. Res., 110, D18309, doi:10.1029/2005JD005900, 2005.

Monier, E. and Weare, B. C.: Climatology and trends in the forcing of the stratospheric ozone transport, Atmos. Chem. Phys., 11, 6311-6323, doi:10.5194/acp-11-6311-2011, 2011.

Newman, P. A., Kawa, S. R., and Nash, E. R.: On the size of the Antarctic ozone hole, Geophys. Res. Lett., 31, L21104, doi:10.1029/2004GL020596, 2004.

NOAA (National Oceanic and Atmospheric Administration): Southern Hemisphere Winter Summary 2008. Climate Prediction Center of NOAA/National Weather Center, National Centers for Environmental Prediction, available at: www.cpc. noaa.gov/products/stratosphere/winter_bulletins/sh_08/ (last access: 30 June 2011), 2009.

Randel, W. J.: The seasonal evolution of planetary waves in the southern hemisphere stratosphere and troposphere, Q. J. Roy. Meteor. Soc., 114, 1385-1409, 1988.

Randel, W. J. and Cobb, J. B.: Coherent variations of monthly mean total ozone and lower stratospheric temperature, J. Geophys. Res., 99, 5433-5447, 1994.

Randel, W. J. and Wu, F.: Cooling of the Arctic and Antarctic polar stratospheres due to ozone depletion, J. Climate, 12, 1467-1479, 1999.

Randel, W. J., Wu, F., and Stolarski, R.: Changes in column ozone correlated with the stratospheric EP flux, J. Meteorol. Soc. Jpn., 80, 849-862, 2002.

Roscoe, H. K., Feng, W., Chipperfield, M. P., Trainic, M., and Shuckburgh, E. F.: The existence of the edge region of the Antarctic stratospheric vortex, J. Geophys. Res., 117, D04301, doi:10.1029/2011JD015940, 2012.

Salby, M. L.: Fundamentals of Atmospheric Physics, edited by: Dmowska, R. and Holton, R., Academic Press, San Diego, USA, 627 pp., 1996.

Salby, M. L. and Callaghan, P. F.: Interannual changes of the stratospheric circulation: influence on the Tropics and Southern Hemisphere, J. Climate, 17, 952-964, 2004.

Sato, K., Tomikawa, Y., Hashida, G., Yamanouchi, T., Nakajima, H., and Sugita, T.: Longitudinally dependent ozone increase in the Antarctic polar vortex revealed by balloon and satellite observations, J. Atmos. Sci., 66, 1807-1820, doi:10.1175/2008JAS2904.1, 2009.

Shanklin, J., Moore, C., and Colwell, S.: Meteorological observing and climate in the British Antarctic Territory and South Georgia: Part 1, Weather, 64, 127-134, doi:10.1002/wea.391, 2009a.

Shanklin, J., Moore, C., and Colwell, S.: Meteorological observing and climate in the British Antarctic Territory and South Georgia: Part 2, Weather, 64, 171-177, doi:10.1002/wea.398, 2009b.

Shindell, D. T., Wong, S., and Rind, D.: Interannual variability of the Antarctic ozone hole in a GCM. Part I: The influence of tropospheric wave variability, J. Atmos. Sci., 54, 2308-2319, 1997.

Sinnhuber, B.-M., von der Gathen, P., Sinnhuber, M., Rex, M., König-Langlo, G., and Oltmans, S. J.: Large decadal scale changes of polar ozone suggest solar influence, Atmos. Chem. Phys., 6, 1835-1841, doi:10.5194/acp-6-1835-2006, 2006.

Solomon, S., Portmann, R. W., Sasaki, T., Hofmann, D. J., and Thompson, D. W. J.: Four decades of ozonesonde measurements over Antarctica, J. Geophys. Res., 110, D21311, doi:10.1029/2005JD005917, 2005. 
Sonkaew, T., von Savigny, C., Eichmann, K.-U., Weber, M., Rozanov, A., Bovensmann, H., and Burrows, J. P.: Chemical ozone loss in Arctic and Antarctic polar winter/spring season derived from SCIAMACHY limb measurements 2002-2009, Atmos. Chem. Phys. Discuss., 11, 6555-6599, doi:10.5194/acpd11-6555-2011, 2011.

Tully, M. B., Klekociuk, A. R., Deschamps, L. L., Henderson, S. I., Krummel, P. B., Fraser, P. J., Shanklin, J. D., Downey, A. H., Gies, H. P., and Javorniczky, J.: The 2007 Antarctic ozone hole, Aust. Meteorol. Mag., 57, 279-298, 2008.

van der A, R. J., Allaart, M. A. F., and Eskes, H. J.: Multi sensor reanalysis of total ozone, Atmos. Chem. Phys., 10, 11277-11294, doi:10.5194/acp-10-11277-2010, 2010.

Varotsos, C.: The Southern Hemisphere ozone hole split in 2002, Environ. Sci. Pollut. R., 9, 375-376, 2002.

Waugh, D. W. and Randel, W. J.: Climatology of Arctic and Antarctic vortices using elliptical diagnostics, J. Atmos. Sci., 56, 15941613, 1999.
Weber, M., Dikty, S., Burrows, J. P., Garny, H., Dameris, M., Kubin, A., Abalichin, J., and Langematz, U.: The Brewer-Dobson circulation and total ozone from seasonal to decadal time scales, Atmos. Chem. Phys., 11, 11221-11235, doi:10.5194/acp-1111221-2011, 2011.

Wilks, D. S.: Statistical methods in the atmospheric sciences, Third Edition, International Geophysics Series, 100, Academic Press, Elsevier Inc., Oxford, UK, 676 pp., 2011.

Wirth, V.: Quasi-stationary planetary waves in total ozone and their correlation with lower stratospheric temperature, J. Geophys. Res., 98, 8873-8882, 1993.

WMO (World Meteorological Organization): Antarctic Ozone Bulletin, No. 4, available at: http://www.wmo.int/pages/prog/arep/ documents/ant-bulletin-4-2010.pdf (last access: 30 June 2011), 2010 . 